\title{
Hypoglycemic and Hypolipidemic Potential of a High Fiber Diet in Healthy versus Diabetic Rabbits
}

\author{
Raquel Díez, Juan J. García, M. José Diez, Matilde Sierra, Ana M. Sahagún, \\ Ángela P. Calle, and Nélida Fernández \\ Department of Pharmacology, Institute of Biomedicine (IBIOMED), University of León, 24071 León, Spain \\ Correspondence should be addressed to Raquel Díez; rdielz@unileon.es
}

Received 11 February 2013; Accepted 11 April 2013

Academic Editor: Kazim Husain

Copyright (c) 2013 Raquel Díez et al. This is an open access article distributed under the Creative Commons Attribution License, which permits unrestricted use, distribution, and reproduction in any medium, provided the original work is properly cited.

\begin{abstract}
The aim of this study was to investigate potential hypoglycaemic and hypolipidemic effects of Plantago ovata husk included in the diet, in healthy and diabetic rabbits. We also examined the effects of this fiber in other biochemical parameters. Two groups of 18 rabbits were used. The first group was fed with standard chow and the second with chow supplemented with Plantago ovata husk ( $3.5 \mathrm{mg} / \mathrm{kg} /$ day). On day 14 diabetes mellitus was induced by the intravenous administration of alloxan $(80 \mathrm{mg} / \mathrm{kg})$. After an oral glucose load ( $3 \mathrm{~g})$, glucose, insulin, and other biochemical parameters were determined on day 14 (healthy rabbits) and on day 28 (diabetic rabbits). In healthy rabbits, fiber did not modify glucose or insulin levels but decreased significantly total cholesterol, LDL-cholesterol, atherogenic index, and glycosylated hemoglobin. In diabetic rabbits, fiber was more beneficial in mild diabetics than in severe diabetics with significant decreases in glucose levels and increases in insulin concentrations. In these animals fiber caused an important reduction in cholesterol, indicating a beneficial effect of Plantago ovata husk in diabetic rabbits. Although further studies in patients are necessary, we think that Plantago ovata husk offers interesting perspectives to be administered to patients with diabetes mellitus.
\end{abstract}

\section{Introduction}

Natural products have been a source of medicinal treatments for thousand of years, and plants-based systems continue to play an essential role in the primary health care of approximately $80 \%$ of the world's underdeveloped and developing countries [1].

Since Burkitt et al. [2] suggested that the lack of fiber might be the common origin of various diseases, its consumption has focused on the prevention and treatment of gastrointestinal disorders [3-5], some types of cancer [3, 6], hyperlipidemia $[3,7]$, cardiovascular diseases $[3,8]$, obesity $[3,9]$, and diabetes $[3,10,11]$.

Viscous forms of dietary fiber have been shown to improve blood glucose control $[12,13]$ by trapping ingested carbohydrates inside the viscous gel formed after digestion.

Psyllium or ispaghula husk (the husk of the seeds of Plantago ovata) is a mixture of neutral and acid polysaccharides with a rest of galacturonic acid. The polysaccharides are built up of the monomers D-xylose and L-arabinose, and ispaghula husk contains $67 \%$ pentosans. Ispaghula husk is a gel-forming (water-soluble) fiber whose benefits in terms of treatment for constipation are well established since many years ago.

Several authors have shown that this fiber reduces postprandial glucose concentrations [10, 12, 14-24]; however, others did not find any modification in postprandial glucose and insulin concentrations, neither in healthy subjects nor in type 2 diabetic patients [25].

Diabetes mellitus will be a major health problem in the 21 st century because its prevalence is increasing worldwide. The prevalence of diabetes mellitus was estimated to be 177 million cases in 2000 and is projected to increase to 366 million by 2030 , largely owing to an aging population, increased urbanization, and more sedentary lifestyles [26].

The important goal of diabetes mellitus treatment is to keep blood glucose, lipid, and lipoprotein levels close to normal, resulting in a reduction of coronary artery disease, a delay in onset, and a major slowing in the progression of complications [27]. Blood glucose control is of established benefit and remains a central tenet of long-term management 
for patients with diabetes mellitus. The risk of developing long-term complications can be substantially reduced with the implementation of intensive glycemic control.

Although sulphonylureas, biguanides, insulin sensitizers (thiazolidinediones), and other current drugs are valuable in the treatment of type 2 diabetes mellitus, their use is restricted by cost, limited pharmacokinetic properties, secondary failure rates, and accompanying side effects [28].

The purpose of this study was to investigate potential hypoglycaemic and hypolipidemic effects of Plantago ovata husk included in the diet, in healthy and diabetic rabbits. We also examined the effects of this fiber in other biochemical parameters such as uric acid, atherogenic index, iron, and calcium.

\section{Material and Methods}

2.1. Animals and Experimental Procedures. Thirty-six healthy male New Zealand white rabbits weighting $2.650-3.240 \mathrm{~kg}$ were used. The animals were housed in individual metal cages, which allowed the isolation of faeces in a lower container to avoid coprophagia. The environmental conditions were as follows: temperature $19 \pm 2^{\circ} \mathrm{C}$, relative humidity $55 \pm$ $10 \%$, and a $12 \mathrm{~h}$ light-dark cycle. Rabbits were maintained under these conditions at least 1 week before the assay, with free access to water and standard laboratory chow. The diet (compound feed for rabbits J-59, Alse) was specially prepared by Piensos Alse (León, Spain) by mixing the following ingredients: carbohydrate, $61.2 \%$; protein, $14.5 \%$; oils and fats, $3.8 \%$; crude fiber, $12.8 \%$; ash, $6.5 \%$; calcium, $0.5 \%$; phosphorus, $0.5 \%$; sodium, $0.2 \%$; vitamin, and trace elements.

The animals were randomized into two groups (groups 1 and 2) of 18 rabbits each. All the animals of the first group received standard chow and the rabbits of the second group received standard chow supplemented with Plantago ovata husk (the husk obtained from the seeds of Plantago ovata). This fiber was added to the chow to provide dose of $3.5 \mathrm{mg} / \mathrm{kg} /$ day to the rabbits.

The study began feeding the animals with the chow during two weeks. On day 14, and after an overnight fast, animals received an oral $3 \mathrm{~g}$ glucose load. After the administration, blood samples were collected at different times to obtain the glucose and insulin curves in healthy animals. A blood sample at time zero was also collected for the determination of the following biochemical parameters: glucose, total cholesterol, LDL-cholesterol, HDL-cholesterol, triglycerides, atherogenic index, glycosylated hemoglobin, uric acid, iron, calcium, phosphorus, magnesium chloride, sodium, and potassium. Blood samples $(1 \mathrm{~mL})$ were obtained from the marginal ear vein, using an intravenous catheter, at $0,30,60,120$, and 180 minutes after glucose administration. Immediately after collection, plasma was separated by centrifugation and stored at $-20^{\circ} \mathrm{C}$ until analyzed.

At the end of the sampling collection, diabetes mellitus was induced by the intravenous administration of alloxan $(80 \mathrm{mg} / \mathrm{kg})$ dissolved in $10 \mathrm{~mL} \mathrm{NaCl}$ solution in the marginal ear vein. Immediately, $2 \mathrm{~mL}$ dextrose $5 \%$ was injected, and this administration was repeated at 20 minutes, 4, 6, and 8 hours after alloxan injection.
Blood glucose concentrations were monitored for two weeks until diabetes was stabilized. After diabetes stabilization and an overnight fast, on day 28 , the rabbits received a new $3 \mathrm{~g}$ oral glucose load, and the determination of glucose and insulin concentrations repeated. As well, the same biochemical parameters were evaluated.

All studies were performed in accordance with the Spanish Regulations for the handling and use of laboratory animals (RD 1201/2005). Minimum number of animals and duration of observation required to obtain consistent data were employed.

The measurement of glucose and the other biochemical parameters was carried out by using a biochemical autoanalyzer (Cobas Integra 400). Insulin was determined by a radiometric method using a kit (Mercodia Ultrasensitive Insulin ELISA, Biosource Europe, SA).

Arithmetic means, SDs, and CVs were calculated from the results measured. Areas under the concentration (AUC) curves were calculated by trapezoidal rule for blood glucose and insulin concentrations from time zero to the last determined sample time. Maximum plasma glucose and insulin concentration $\left(C_{\max }\right)$ and the time to reach maximum concentration $\left(t_{\max }\right)$ were read directly from the individual plasma concentration-time curves.

Statistical Analysis. The data obtained for the two groups (animals receiving standard chow or supplemented with Plantago ovata husk) were compared for statistical significance by $t$ test, at $P \leq 0.05$. All analyses were performed by using SPSS Statistics 17.0 for Windows.

\section{Results}

3.1. Serum Glucose. The values of the mean plasma glucose concentrations as a function of time obtained after the oral administration of a $3 \mathrm{~g}$ glucose load on day 14 (healthy rabbits) to animals fed with standard chow (group 1) or supplemented with Plantago ovata husk (group 2) are shown in Figure 1. In this figure, glucose mean plasma concentrations obtained on day 28 (mild and severe diabetic animals) can be also seen. On day 28, when diabetes was stabilized, the animals were divided in two groups: severe diabetics and mild diabetics. The rabbits showing fasting blood glucose values $250 \mathrm{mg} / \mathrm{dL}$ or above were considered as severe diabetic rabbits group and those with values between 120 and $250 \mathrm{mg} / \mathrm{dL}$ were considered as mild diabetic rabbits group [29].

In healthy rabbits (day 14), the presence of fiber in the chow did not modify glucose concentrations, being very similar in both groups. When the rabbits were made diabetics (day 28) fiber caused a more important reduction in concentrations, higher in mild diabetic animals as shown in the figure. There were no significant differences between groups 1 and 2 (day 14) in these parameters for healthy animals.

Table 1 includes the values of $t_{\max }, C_{\max }$, and AUC determined for glucose in group 1 (standard chow) and group 2 (fiber supplemented) on day 14 (healthy rabbits) as well as on day 28 (mild and severe diabetic rabbits).

The presence of fiber in the chow (day 28) reduced the values of $C_{\max }$ and $\mathrm{AUC}$ in both mild and severe 
TABLE 1: Pharmacokinetic parameters for glucose obtained on days 14 (healthy rabbits) and 28 (diabetic rabbits) after the administration of an oral 3 g glucose load.

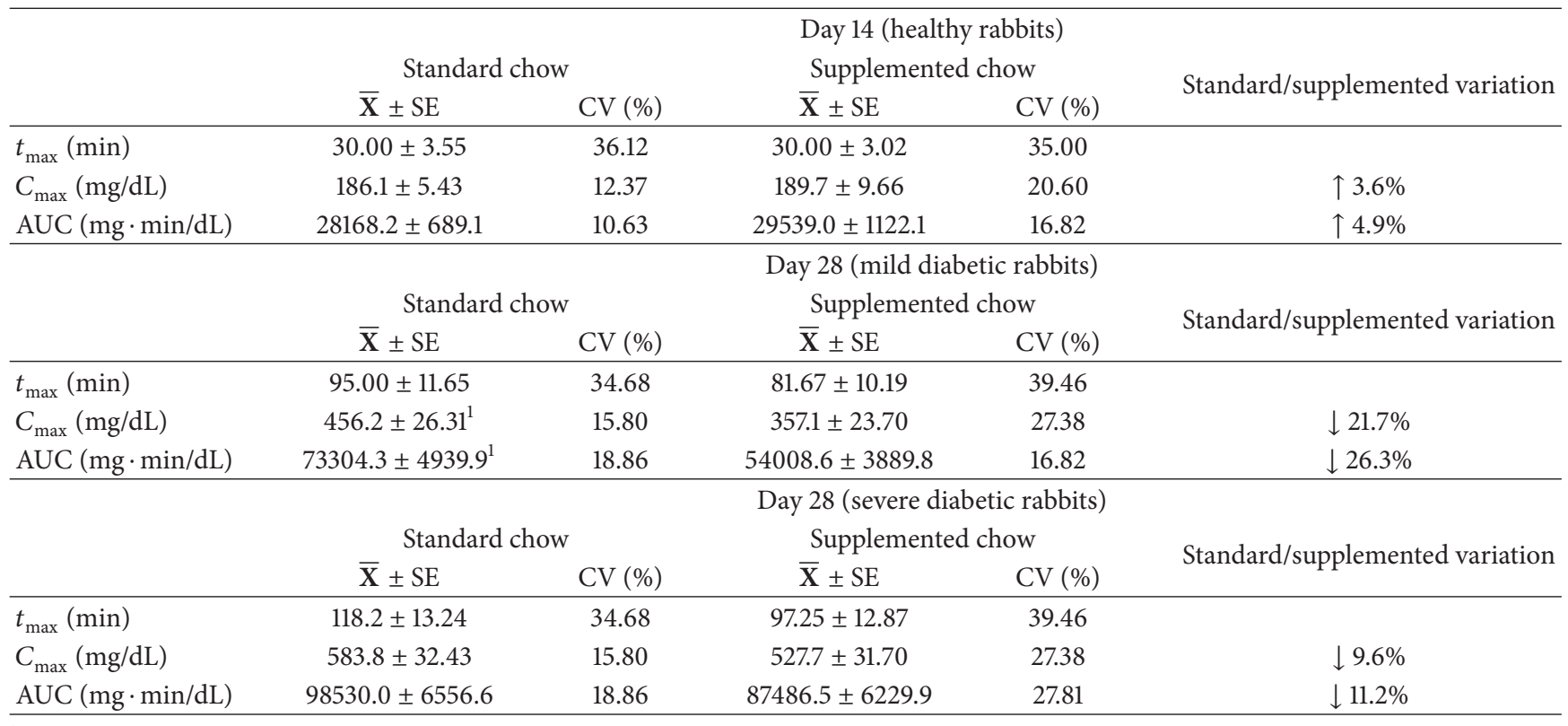

${ }^{1}$ Significative differences $(t$-test, $P \leq 0.05)$.

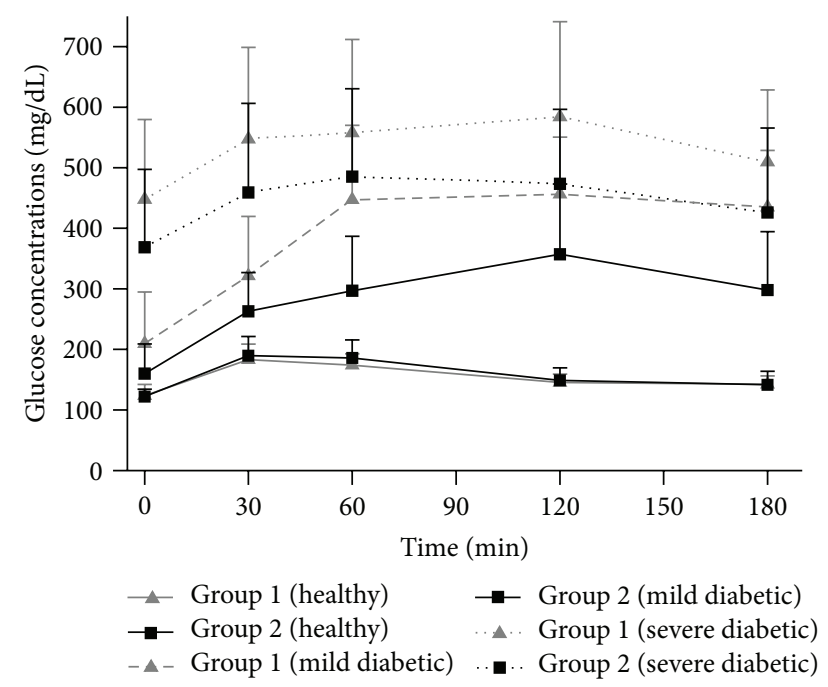

FIGURE 1: Mean \pm SD plasma glucose concentrations in healthy, mild diabetic, and severe diabetic rabbits after the administration of an oral $3 \mathrm{~g}$ glucose load with standard chow (group 1) or supplemented chow (group 2).

diabetic rabbits. This reduction was more important in mild diabetic rabbits, being $21.7 \%$ for $C_{\max }$ and $26.3 \%$ for AUC (significant differences, $t$-test, $P \leq 0.05$ ) and lower in severe diabetic animals $\left(9.6 \%\right.$ for $C_{\max }$ and $11.2 \%$ for AUC) with no significant differences. It was also observed that $t_{\max }$ was reached before $(13.3 \mathrm{~min}$. in mild diabetics and $21 \mathrm{~min}$. in severe diabetics) although differences were not significant.

3.2. Serum Insulin. Figure 2 shows the values of the mean plasma insulin concentrations as a function of time obtained

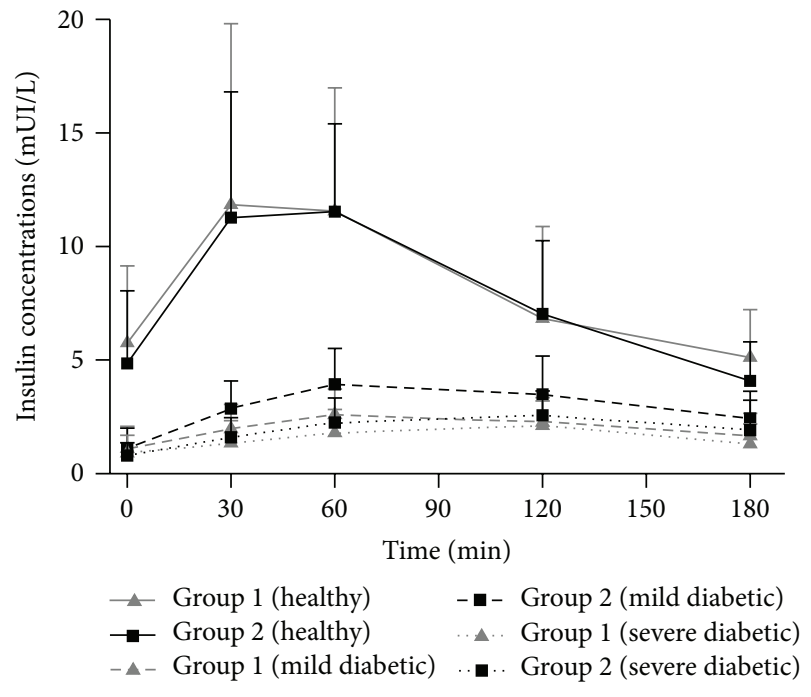

FIGURE 2: Mean \pm SD plasma insulin concentrations in healthy, mild diabetic, and severe diabetic rabbits after the administration of an oral $3 \mathrm{~g}$ glucose load with standard chow (group 1) or supplemented chow (group 2).

after the oral administration of a $3 \mathrm{~g}$ glucose load to rabbits fed with standard chow (group 1) or supplemented with Plantago ovata husk (group 2) on day 14 (healthy animals) and on day 28 (diabetic rabbits). The presence of fiber in chow did not modify insulin levels in healthy rabbits; however, in diabetic animals fiber caused an increase in insulin concentrations, higher in mild diabetics.

Table 2 includes the values of $t_{\max }, C_{\max }$, and AUC determined for insulin in group 1 and group 2 on day 14 . As can be seen in this table, in healthy rabbits, the inclusion of Plantago 
TABLE 2: Pharmacokinetic parameters for insulin obtained on days 14 (healthy rabbits) and 28 (diabetic rabbits) after the administration of an oral $3 \mathrm{~g}$ glucose load.

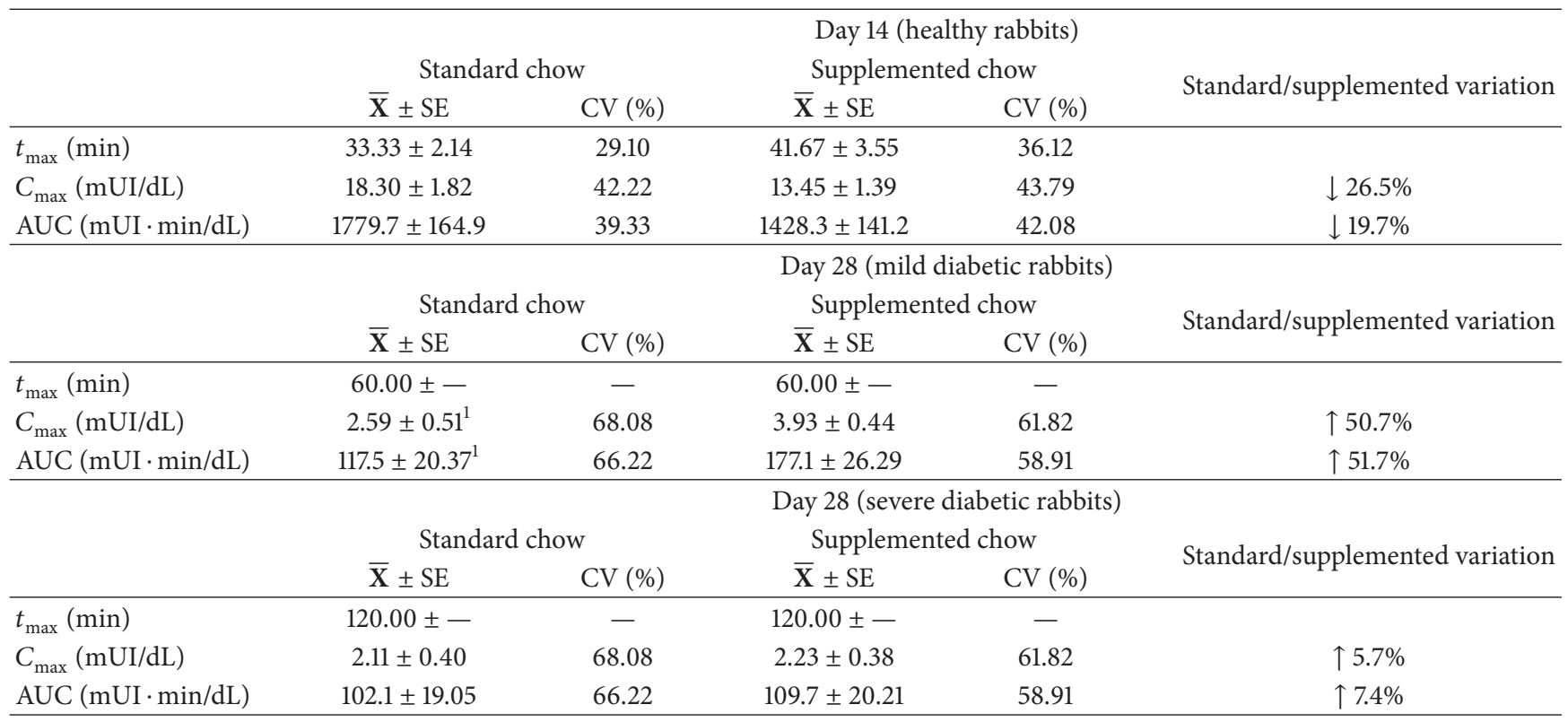

${ }^{1}$ Significative differences $(t$-test, $P \leq 0.05)$.

TABLE 3: Biochemical parameters obtained on day 14 (healthy rabbits).

\begin{tabular}{|c|c|c|c|}
\hline Healthy rabbits & Standard chow $(\overline{\mathbf{X}} \pm \mathrm{SE})$ & Supplemented chow $(\overline{\mathbf{X}} \pm \mathrm{SE})$ & Standard/supplemented variation \\
\hline Cholesterol (mg/dL) & $68.31 \pm 5.33$ & $58.40 \pm 6.14$ & $\downarrow 14.5 \%^{1}$ \\
\hline LDL-cholesterol (mg/dL) & $46.45 \pm 3.14$ & $39.71 \pm 3.61$ & $\downarrow 14.5 \%^{1}$ \\
\hline HDL-cholesterol (mg/dL) & $33.24 \pm 1.44$ & $32.06 \pm 1.63$ & $\downarrow 3.5 \%$ \\
\hline Triglycerides (mg/dL) & $85.50 \pm 8.39$ & $77.65 \pm 6.49$ & $\downarrow 9.2 \%$ \\
\hline Atherogenic index & $2.06 \pm 0.16$ & $1.66 \pm 0.12$ & $\downarrow 19.1 \%^{1}$ \\
\hline Uric acid (mg/dL) & $0.11 \pm 0.02$ & $0.11 \pm 0.01$ & - \\
\hline Glycosylated hemoglobin (\%) & $2.93 \pm 0.40$ & $2.31 \pm 0.27$ & $\downarrow 21.0 \%^{1}$ \\
\hline $\mathrm{Ca}(\mathrm{mg} / \mathrm{dL})$ & $13.36 \pm 0.16$ & $13.24 \pm 0.16$ & $\downarrow 0.9 \%$ \\
\hline $\mathrm{P}(\mathrm{mg} / \mathrm{dL})$ & $8.75 \pm 0.13$ & $8.16 \pm 0.06$ & $\downarrow 6.7 \%$ \\
\hline $\operatorname{Mg}(\mathrm{mg} / \mathrm{dL})$ & $2.76 \pm 0.10$ & $2.67 \pm 0.10$ & $\downarrow 3.3 \%$ \\
\hline $\mathrm{Cl}(\mathrm{mg} / \mathrm{dL})$ & $100.43 \pm 0.87$ & - & - \\
\hline $\mathrm{Na}(\mathrm{mg} / \mathrm{dL})$ & $142.52 \pm 0.85$ & $142.95 \pm 0.90$ & $\downarrow 0.3 \%$ \\
\hline $\mathrm{K}(\mathrm{mg} / \mathrm{dL})$ & $4.32 \pm 0.10$ & $4.09 \pm 0.08$ & $\downarrow 5.3 \%$ \\
\hline $\mathrm{Fe}(\mathrm{mg} / \mathrm{dL})$ & $120.0 \pm 2.83$ & $122.95 \pm 8.23$ & $\downarrow 2.5 \%$ \\
\hline
\end{tabular}

${ }^{1}$ Significative differences $(t$-test, $P \leq 0.05)$.

ovata husk in the chow reduced by $26.5 \%$ the value of $C_{\max }$, although differences were not significant. AUC was also lower in the presence of fiber $(19.7 \%)$, and $t_{\max }$ was reached later (8 min.), although these differences were not significant.

The changes caused by the presence of fiber in the feeding of mild diabetic rabbits were more important than in severe diabetic rabbits. There was a significant increase $(t$ test, $P \leq 0.05)$ in $C_{\max }(50.7 \%)$ and in AUC (51.7\%) with no modification in $t_{\max }$ for mild diabetic rabbits. In severe diabetics, these increases were much lower $(5.7 \%$ and $7.4 \%$, resp., for $C_{\max }$ and AUC). The value of $t_{\max }$ was not modified by the presence of Plantago ovata husk and was higher than that in mild diabetics.
3.3. Other Biochemical Parameters. The values of different biochemical parameters evaluated in healthy rabbits (day 14) are included in Table 3.

All parameters were lower in group 2 (fiber included in chow) than in group 1 (standard diet), although the differences only were significant for total cholesterol, LDLcholesterol, atherogenic index, and glycosylated hemoglobin ( $t$-test, $P \leq 0.05)$.

Biochemical parameters values for mild diabetic rabbits are shown in Table 4. In these animals, all values, except iron, were lower in animals fed with chow supplemented with fiber, being the differences significant for total cholesterol, LDLcholesterol, HDL-cholesterol, triglycerides, glycosylated 
TABLE 4: Biochemical parameters obtained on day 28 (mild diabetic rabbits).

\begin{tabular}{|c|c|c|c|}
\hline Mild diabetic rabbits & Standard chow $(\overline{\mathbf{X}} \pm \mathrm{SE})$ & Supplemented chow $(\overline{\mathbf{X}} \pm \mathrm{SE})$ & Standard/supplemented variation \\
\hline Cholesterol (mg/dL) & $84.83 \pm 18.04$ & $70.25 \pm 11.84$ & $\downarrow 17.2 \%^{1}$ \\
\hline LDL-cholesterol (mg/dL) & $57.70 \pm 3.92$ & $47.80 \pm 2.81$ & $\downarrow 20.6 \%^{1}$ \\
\hline HDL-cholesterol (mg/dL) & $22.67 \pm 2.93$ & $16.0 \pm 2.64$ & $\downarrow 20.6 \%^{1}$ \\
\hline Triglycerides (mg/dL) & $289.0 \pm 20.45$ & $148.25 \pm 19.41$ & $\downarrow 48.7 \%^{1}$ \\
\hline Atherogenic index & $3.24 \pm 0.36$ & $3.07 \pm 0.62$ & $\downarrow 5.2 \%$ \\
\hline Uric acid (mg/dL) & $0.16 \pm 0.02$ & $0.09 \pm 0.02$ & $\downarrow 45.9 \%^{1}$ \\
\hline Glycosylated hemoglobin (\%) & $6.41 \pm 0.04$ & $4.80 \pm 0.02$ & $\downarrow 25.1 \%^{1}$ \\
\hline $\mathrm{Ca}(\mathrm{mg} / \mathrm{dL})$ & $12.54 \pm 0.32$ & $12.04 \pm 0.32$ & $\downarrow 4.0 \%$ \\
\hline $\mathrm{P}(\mathrm{mg} / \mathrm{dL})$ & $7.78 \pm 0.13$ & $6.26 \pm 0.11$ & $\downarrow 19.5 \%$ \\
\hline $\mathrm{Mg}(\mathrm{mg} / \mathrm{dL})$ & $2.38 \pm 0.09$ & $2.14 \pm 0.12$ & $\downarrow 10.1 \%$ \\
\hline $\mathrm{Cl}(\mathrm{mg} / \mathrm{dL})$ & $88.0 \pm 6.24$ & - & - \\
\hline $\mathrm{Na}(\mathrm{mg} / \mathrm{dL})$ & $136.0 \pm 0.85$ & $136.20 \pm 1.06$ & $\uparrow 0.1 \%$ \\
\hline $\mathrm{K}(\mathrm{mg} / \mathrm{dL})$ & $3.86 \pm 0.42$ & $3.53 \pm 0.06$ & $\downarrow 8.6 \%$ \\
\hline $\mathrm{Fe}(\mathrm{mg} / \mathrm{dL})$ & $67.0 \pm 4.14$ & $80.67 \pm 7.43$ & $\uparrow 17.0 \%$ \\
\hline
\end{tabular}

${ }^{1}$ Significative differences $(t$-test, $P \leq 0.05)$.

TABLE 5: Biochemical parameters obtained on day 28 (severe diabetic rabbits).

\begin{tabular}{|c|c|c|c|}
\hline Severe diabetic rabbits & Standard chow $(\overline{\mathbf{X}} \pm \mathrm{SE})$ & Supplemented chow $(\overline{\mathbf{X}} \pm \mathrm{SE})$ & Standard/supplemented variation \\
\hline Cholesterol (mg/dL) & $317.18 \pm 32.97$ & $182.09 \pm 15.60$ & $\downarrow 42.6 \%^{1}$ \\
\hline LDL-cholesterol (mg/dL) & $215.70 \pm 17.23$ & $123.80 \pm 9.70$ & $\downarrow 31.6 \%^{1}$ \\
\hline HDL-cholesterol (mg/dL) & $29.79 \pm 3.46$ & $20.38 \pm 3.09$ & $\downarrow 31.6 \%{ }^{1}$ \\
\hline Triglycerides (mg/dL) & $715.97 \pm 128.56$ & $527.43 \pm 89.87$ & $\downarrow 26.3 \%^{1}$ \\
\hline Atherogenic index & $8.71 \pm 1.67$ & $6.90 \pm 0.45$ & $\downarrow 20.8 \%^{1}$ \\
\hline Uric acid (mg/dL) & $0.23 \pm 0.03$ & $0.08 \pm 0.02$ & $\downarrow 66.0 \%^{1}$ \\
\hline Glycosylated hemoglobin (\%) & $6.46 \pm 0.05$ & $4.93 \pm 0.05$ & $\downarrow 23.6 \%^{1}$ \\
\hline $\mathrm{Ca}(\mathrm{mg} / \mathrm{dL})$ & $12.86 \pm 0.54$ & $11.70 \pm 0.52$ & $\downarrow 9.0 \%$ \\
\hline $\mathrm{P}(\mathrm{mg} / \mathrm{dL})$ & $8.22 \pm 0.27$ & $6.0 \pm 0.19$ & $\downarrow 27.0 \%^{1}$ \\
\hline $\operatorname{Mg}(\mathrm{mg} / \mathrm{dL})$ & $2.84 \pm 0.09$ & $2.15 \pm 0.08$ & $\downarrow 24.3 \%^{1}$ \\
\hline $\mathrm{Cl}(\mathrm{mg} / \mathrm{dL})$ & $83.40 \pm 5.63$ & - & - \\
\hline $\mathrm{Na}(\mathrm{mg} / \mathrm{dL})$ & $133.22 \pm 8.31$ & $137.22 \pm 5.64$ & $\downarrow 3.0 \%$ \\
\hline $\mathrm{K}(\mathrm{mg} / \mathrm{dL})$ & $3.54 \pm 0.05$ & $3.44 \pm 0.04$ & $\downarrow 2.8 \%$ \\
\hline $\mathrm{Fe}(\mathrm{mg} / \mathrm{dL})$ & $87.10 \pm 4.30$ & $102.0 \pm 4.13$ & $\downarrow 14.6 \%$ \\
\hline
\end{tabular}

${ }^{1}$ Significative differences $(t$-test, $P \leq 0.05)$.

hemoglobin, and uric acid ( $t$-test, $P \leq 0.05)$. Triglycerides $(48.7 \%)$ and uric acid (45.9\%) were the parameters that showed the highest reduction.

Table 5 includes the values for these biochemical parameters in severe diabetic rabbits. In this group of animals, the decreases observed in all parameters in supplemented chow group were higher, being the highest decreases for uric acid $(66 \%)$ and total cholesterol (42.6\%). There were significant differences in total cholesterol, LDL-cholesterol, HDL-cholesterol, triglycerides, atherogenic index, glycosylated hemoglobin, uric acid, phosphorus, and magnesium $(t-$ test, $P \leq 0.05)$.

\section{Discussion}

4.1. Glucose. According to Quesenberry and Carpenter [30] and Kahn [31], rabbit's fasting glucose ranges from $75 \mathrm{mg} / \mathrm{dL}$ to $155 \mathrm{mg} / \mathrm{dL}$, values very similar to those found in this study, varied from $79.4 \mathrm{mg} / \mathrm{dL}$ to $156.0 \mathrm{mg} / \mathrm{dL}$. The presence of fiber (Plantago ovata husk) in the chow of these healthy rabbits modified significantly neither basal nor postprandial glucose levels although a slight reduction was observed.
In the bibliographical review, we have not found any study regarding the effect of dietary fiber on glucose levels in healthy rabbits. However, the results obtained in other experimental animals were similar to ours. Thus, in sows, after the inclusion of a fermentable dietary fiber, postprandial glucose levels were reduced without modifying its basal concentrations [32]. Adding purified soluble (pectin) or insoluble (lignocellulose) fiber to a corn meal did not affect postprandial glucose responses in healthy horses, while AUC and $C_{\max }$ values were slightly higher with this meal [33]. In healthy volunteers, the results are variable. In this way, Sierra et al. [23] showed that the administration of Plantago ovata husk may be beneficial due to its ability to reduce glucose postprandial concentrations. The authors find that the AUC curve obtained for glucose after the administration of a $50 \mathrm{~g}$ glucose load was reduced by $11.1 \%$ (significant differences) in the presence of Plantago ovata husk and 2.6\% with gum guar (no significant differences). Aller et al. [34] suggested that a modest increase in soluble fiber intake in healthy subjects for 3 months improved glucose levels. Other study [35] demonstrated that the addition of a highly viscous fiber 
to a starchy snack during 2 weeks is able to reduce the glycemic response in healthy volunteers [36], and Kim et al. [37] also suggested that glucose response was not significantly different when adding $\beta$-glucan to meal.

Several studies have been carried out using experimental alloxan-induced diabetic rabbits. In these animals, fasting glucose was determined, being the values obtained very similar to ours. Thus, Annamala and Augusti [38] showed average values of $329.1 \mathrm{mg} / \mathrm{dL}$ and Lenich et al. [39] determined glucose values between 368 and $380 \mathrm{mg} / \mathrm{dL}$. Schiller and McNamara [40] considered as hyperglycaemic rabbits those with basal glucose between 170 and $400 \mathrm{mg} / \mathrm{dL}$ and diabetics when values were above $400 \mathrm{mg} / \mathrm{dL}$. Fleitas et al. [41] obtained basal values for glucose above $252 \mathrm{mg} / \mathrm{dL} 2$ days after alloxan-induced diabetes and Godwin et al. [42] indicated a mean value of $334.0 \mathrm{mg} / \mathrm{dL}$.

In the present study, the results obtained showed that the inclusion of Plantago ovata husk in the feeding of diabetic rabbits was more beneficial in mild diabetics than in severe diabetics with significant decreases in glucose levels.

Other authors showed that the inclusion of this soluble fiber in food of diabetic mice significantly reduced glucose basal levels in relation to mice that were fed without fiber [43]. In type 2 diabetic patients, supplemented with $5.1 \mathrm{~g}$ of psyllium or cellulose placebo twice daily for 8 weeks, other authors found postlunch postprandial glucose concentration was $19.2 \%$ lower in the psyllium than in the placebo group [21]. Sierra et al. [11] evaluated the effects of psyllium in type 2 diabetic patients. All volunteers received $3.5 \mathrm{~g}$ of psyllium four times a day during 6 weeks and the last day, after overnight fast, ingested a standard breakfast. Before breakfast, one dose of the fiber was given. It was demonstrated that glucose absorption decreased significantly in the presence of psyllium (12.2\%). Ziai et al. [44] showed that 8 weeks of treatment with $5.1 \mathrm{~g}$ of psyllium twice a day can reduce plasma glucose and fluctuations in blood glucose control.

It was observed that other fibers also modified glucose response. In this way, another author after glucose load in diabetic rats with soybean fiber chow found significantly delayed $t_{\max }$ against control group [45]. Similarly, 10-20\% guar gum supplemented diets significantly decreased glucose plasma concentrations in diabetic rats [46].

Guar gum and wheat bran dietary inclusion for 2 months reduced significantly urinary glucose excretion and fasting glucose in type 2 diabetic patients [47].

4.2. Insulin. Schiller and McNamara [40] found basal mean insulin concentrations of $33 \mathrm{mUI} / \mathrm{L}$, higher than those found in our rabbits. The basal values determined by Kawai et al. [48] were $3.82 \mathrm{mUI} / \mathrm{L}$. Our results showed that the presence of fiber in the chow of healthy rabbits did not modify insulin levels. As occurred with glucose, we did not found any work about dietary fiber's effects in insulin levels from healthy rabbits.

In sows, De Leeuw et al. [32] concluded that sugarbeet pulp, as a source of fermentable dietary fiber twice a day, did not change basal insulin levels but stabilized postprandial levels and reduced physical activity in limited-fed sows several hours after feeding. Adding purified soluble $(0.1 \mathrm{~g} / \mathrm{kg} /$ day $)$ or insoluble fiber $(0.2 \mathrm{~g} / \mathrm{kg} /$ day $)$ to a corn meal during 10 days did not affect postprandial insulin response in healthy horses [33]. According to the results obtained for Sierra et al. [23] in healthy women, the administration of glucose $(50 \mathrm{~g})$ and Plantago ovata husk (10.5 g/day) after an overnight fast during 2 days may be beneficial to reduce insulin requirements. In this study, insulin AUC was reduced by $36.1 \%$ when ispaghula husk was administered, and accumulated AUC values were lower when fiber was administered from 30 up to $120 \mathrm{~min}$. Wolever et al. [49] observed in men that plasma insulin was significantly lower after the administration of a high-fiber cereal meal than after giving a low-fiber cereal.

Flood et al. [50] analyzed fasting insulin serum from 750 subjects with (375) and without (375) a low-fat, highfiber, high-fruit, and -vegetable dietary after 4 years, showing that this intervention had minimal impact on serum concentrations of insulin. Kim et al. [37] suggest that acute consumption of $10 \mathrm{~g}$ of $\beta$-glucan is able to induce physiologically beneficial effects on postprandial insulin responses in obese women at risk for insulin resistance.

In alloxan-induced diabetic rabbits, Schiller and McNamara [40] obtained mean baseline insulin values of $9.3 \mathrm{mUI} / \mathrm{L}$. This value is much higher than those obtained in this study (0.464-1.412 mUI/L). Other authors [51] obtained mean baseline insulin values of $6.24 \mathrm{mUI} / \mathrm{L}$.

The inclusion of Plantago ovata husk in the feeding of diabetic rabbits was more beneficial in mild diabetic (significant differences) than in severe diabetic rabbits.

Insulin levels were significantly higher in psyllium-fed than in placebo-fed mice, indicating that this fiber may delay the progression of diabetes in the animal model [43]. Madar [45] studied the effect of brown rice (10\%) and soybean (10\%) dietary fiber on the oral glucose tolerance test in diabetic rats and observed that insulin levels were not affected by the inclusion of fiber in diet. The same conclusion was achieved by Ray et al. [47] after giving a diet with $20 \mathrm{~g}$ of guar gum during 2 months to 12 obese and poor controlled noninsulin-dependent diabetic patients. However, Sierra et al. [11] observed changes in insulin levels (reduction 5\%) in 20 type 2 diabetic patients that receieved $3.5 \mathrm{~g}$ of psyllium four times a day.

The present study shows that the presence of the fiber in the chow modified glucose and insulin levels in diabetic rabbits. The possible mechanism of action of this gel-forming fiber is related to the ability to increase the viscosity of the gastrointestinal contents, and thus, interfering with motility and absorption [52].

4.3. Other Biochemical Parameters. Our parameters showed that the values obtained in group 2 were lower than those found in group 1 . In a study carried out to develop experimental diabetes model in healthy rabbits [53] the authors found average values for total cholesterol and HDL-cholesterol slightly lower than those reported in our study, while triglycerides were higher. The values of total cholesterol and HDLcholesterol reported by Sharma et al. [29] were similar to ours, while LDL-cholesterol was lower. 
In diabetic animals, minerals, sodium, and potassium were within the range indicated by Quesenberry and Carpenter [30], while calcium and phosphorus values were slightly higher.

In severe diabetic rabbits, total cholesterol values were similar to those found by other authors [38], while those of LDL-cholesterol were significantly lower and HDLcholesterol levels much higher.

\section{Conclusions}

In conclusion, the inclusion of Plantago ovata husk in the chow caused an important reduction in glucose levels and an important increase in insulin levels in mild diabetic rabbits. A hypolipidemic effect was also observed.

Although further studies in patients are necessary, we think that Plantago ovata husk offers interesting perspectives to be administered to patients with diabetes mellitus. The administration of this fiber can reduce glucose and increase insulin levels and also improve other parameters, mainly cholesterol that usually shows high levels in diabetics.

\section{Conflict of Interests}

The authors declare that they have no conflict of interests.

\section{Acknowledgment}

The authors wish to thank Madaus, S.A. Laboratory for its collaboration in this study.

\section{References}

[1] H. King, R. E. Aubert, and W. H. Herman, "Global burden of diabetes, 1995-2025: prevalence, numerical estimates, and projections," Diabetes Care, vol. 21, no. 9, pp. 1414-1431, 1998.

[2] D. P. Burkitt, A. R. Walker, and N. S. Painter, "Effect of dietary fibre on stools and the transit-times, and its role in the causation of disease," The Lancet, vol. 2, no. 7792, pp. 1408-1412, 1972.

[3] D. S. Gray, "The clinical uses of dietary fiber," American Family Physician, vol. 51, no. 2, pp. 419-423, 1995.

[4] E. Rojas, "La fibra dietética: estudio bioquímico y aplicaciones clínicas," Alimentos Nutrición y Salud, vol. 4, no. 3, pp. 59-72, 1997.

[5] F. Fernández-Bañares, J. Hinojosa, J. L. Sánchez-Lombrana et al., "Randomized clinical trial of Plantago ovata seeds (dietary fiber) as compared with mesalamine in maintaining remission in ulcerative colitis. Spanish Group for the Study of Crohn's Disease and Ulcerative Colitis (GETECCU)," American Journal of Gastroenterology, vol. 94, no. 2, pp. 427-433, 1999.

[6] J. D. Potter, M. L. Slattery, R. M. Bostick, and S. M. Gapstur, "Colon cancer: a review of the epidemiology", Epidemiologic Reviews, vol. 15, no. 2, pp. 499-545, 1993.

[7] J. W. Anderson, L. D. Allgood, A. Lawrence et al., "Cholesterollowering effects of psyllium intake adjunctive to diet therapy in men and women with hypercholesterolemia: meta-analysis of 8 controlled trials," American Journal of Clinical Nutrition, vol. 71, no. 2, pp. 472-479, 2000.

[8] J. W. Anderson, B. M. Smith, and N. J. Gustafson, "Health benefits and practical aspects of high-fiber diets," American
Journal of Clinical Nutrition, vol. 59, no. 5, pp. 1242S-1247S, 1994.

[9] B. Burton-Freeman, "Dietary fiber and energy regulation," Journal of Nutrition, vol. 130, no. 2, pp. 272S-275S, 2000.

[10] J. W. Anderson and A. O. Akanji, "Dietary fiber-an overview," Diabetes Care, vol. 14, no. 12, pp. 1126-1131, 1991.

[11] M. Sierra, J. J. García, N. Fernández, M. J. Diez, and A. P. Calle, "Therapeutic effects of psyllium in type 2 diabetic patients," European Journal of Clinical Nutrition, vol. 56, no. 9, pp. 830$842,2002$.

[12] D. J. A. Jenkins, T. M. S. Wolever, and A. R. Leeds, "Dietary fibres, fibre analogues, and glucose tolerance: importance of viscosity," British Medical Journal, vol. 1, no. 6124, pp. 1392-1394, 1978.

[13] V. Vuksan, J. L. Sievenpiper, R. Owen et al., "Beneficial effects of viscous dietary fiber from Konjac-Mannan in subjects with the insulin resistance syndrome: results of a controlled metabolic trial," Diabetes Care, vol. 23, no. 1, pp. 9-14, 2000.

[14] D. J. A. Jenkins, A. R. Leeds, and M. A. Gassull, "Decrease in postprandial insulin and glucose concentration by guar and pectin," Annals of Internal Medicine, vol. 86, no. 1, pp. 20-23, 1977.

[15] D. J. A. Jenkins, T. M. S. Wolever, R. H. Taylor, H. M. Barrer, H. Fielden, and A. L. Jenkins, "Effect of guar crispbread with cereal products and leguminous seeds on blood glucose concentrations of diabetics," British Medical Journal, vol. 281, no. 6250, pp. 1248-1250, 1980.

[16] N. K. Fukagawa, J. W. Anderson, G. Hageman, V. R. Young, and K. L. Minaker, "High-carbohydrate, high-fiber diets increase peripheral insulin sensitivity in healthy young and old adults," American Journal of Clinical Nutrition, vol. 52, no. 3, pp. 524528, 1990.

[17] T. M. S. Wolever, V. Vuksan, H. Eshuis et al., "Effect of method of administration of psyllium on glycemic response and carbohydrate digestibility," Journal of the American College of Nutrition, vol. 10, no. 4, pp. 364-371, 1991.

[18] L. M. Chuang, T. S. Jou, W. S. Yang et al., "Therapeutic effect of guar gum in patients with non-insulin-dependent diabetes mellitus," Journal of the Formosan Medical Association, vol. 91, no. 1, pp. 15-19, 1992.

[19] R. M. Fairchild, P. R. Ellis, A. J. Byrne, S. D. Luzio, and M. A. Mir, "A new breakfast cereal containing guar gum reduces postprandial plasma glucose and insulin concentrations in normal-weight human subjects," British Journal of Nutrition, vol. 76, no. 1, pp. 63-73, 1996.

[20] S. L. Brenelli, S. D. S. Campos, and M. J. A. Saad, "Viscosity of gums in vitro and their ability to reduce postprandial hyperglycemia in normal subjects," Brazilian Journal of Medical and Biological Research, vol. 30, no. 12, pp. 1437-1440, 1997.

[21] J. W. Anderson, L. D. Allgood, J. Turner, P. R. Oeltgen, and B. P. Daggy, "Effects of psyllium on glucose and serum lipid responses in men with type 2 diabetes and hypercholesterolemia," American Journal of Clinical Nutrition, vol. 70, no. 4, pp. 466-473, 1999.

[22] M. Sierra, A. P. Calle, N. Fernández et al., "Effect of Ispaghula husk on postprandial glycemia in healthy female volunteers," Nutrición Hospitalaria, vol. 14, no. 5, pp. 197-202, 1999.

[23] M. Sierra, J. J. García, N. Fernández et al., "Effects of Ispaghula husk and guar gum on postprandial glucose and insulin concentrations in healthy subjects," European Journal of Clinical Nutrition, vol. 55, no. 4, pp. 235-243, 2001. 
[24] N. Fernández, M. Sierra, J. J. García, M. J. Diez, and A. González, "Effects of Ispaghula husk on postprandial glucose and insulin concentrations in patients with type 2 diabetes," Methods and Findings in Experimental Clinical Pharmacology, vol. 22, no. 5, p. 104, 2000.

[25] H. A. Jarjis, N. A. Blackburn, J. S. Redfern, and N. W. Read, “The effect of ispaghula (Fybogel and Metamucil) and guar gum on glucose tolerance in man," British Journal of Nutrition, vol. 51, no. 3, pp. 371-378, 1984.

[26] S. Wild, G. Roglic, A. Green, R. Sicree, and H. King, "Global Prevalence of Diabetes: estimates for the year 2000 and projections for 2030," Diabetes Care, vol. 27, no. 5, pp. 1047-1053, 2004.

[27] S. Venkateswaran and L. Pari, "Antioxidant effect of Phaseolus vulgaris in streptozotocin-induced diabetic rats," Asia Pacific Journal of Clinical Nutrition, vol. 11, no. 3, pp. 206-209, 2002.

[28] A. J. Krentz and C. J. Bailey, "Oral antidiabetic agents: current role in type 2 diabetes mellitus," Drugs, vol. 65, no. 3, pp. 385411, 2005.

[29] S. B. Sharma, A. Nasir, K. M. Prabhu, P. S. Murthy, and G. Dev, "Hypoglycaemic and hypolipidemic effect of ethanolic extract of seeds of Eugenia jambolana in alloxan-induced diabetic rabbits," Journal of Ethnopharmacology, vol. 85, no. 2-3, pp. 201206, 2003.

[30] K. E. Quesenberry and J. W. Carpenter, Ferrets, Rabbits and Rodents: Clinical Medicine and Surgery, Elsevier, Maryland Heights, Miss, USA, 2nd edition, 2004.

[31] C. M. Kahn, Ed., The Merck Veterinary Manual, Merck and Co, New Jersey, NJ, USA, 9th edition, 2008.

[32] J. A. De Leeuw, A. W. Jongbloed, and M. W. A. Verstegen, "Dietary fiber stabilizes blood glucose and insulin levels and reduces physical activity in sows (Sus scrofa)," Journal of Nutrition, vol. 134, no. 6, pp. 1481-1486, 2004.

[33] I. Vervuert, S. Klein, and M. Coenen, "Effect of mixing dietary fibre (purified lignocellulose or purified pectin) and a corn meal on glucose and insulin responses in healthy horses," Journal of Animal Physiology and Animal Nutrition, vol. 93, no. 3, pp. 331338, 2009.

[34] R. Aller, D. A. De Luis, O. Izaola et al., "Effect of soluble fiber intake in lipid and glucose leves in healthy subjects: a randomized clinical trial," Diabetes Research and Clinical Practice, vol. 65, no. 1, pp. 7-11, 2004.

[35] A. L. Jenkins, D. J. Jenkins, T. M. Wolever et al., "Comparable postprandial glucose reductions with viscous fiber blend enriched biscuits in healthy subjects and patients with diabetes mellitus: acute randomized controlled clinical trial," Croatian Medical Journal, vol. 49, no. 6, pp. 772-782, 2008.

[36] K. C. Maki, M. H. Davidson, M. S. Witchger, M. R. Dicklin, and P. V. Subbaiah, "Effects of high-fiber oat and wheat cereals on postprandial glucose and lipid responses in healthy men," International Journal for Vitamin and Nutrition Research, vol. 77, no. 5, pp. 347-356, 2007.

[37] H. Kim, K. S. Stote, K. M. Behall, K. Spears, B. Vinyard, and J. M. Conway, "Glucose and insulin responses to whole grain breakfasts varying in soluble fiber, $\beta$-glucan: a dose response study in obese women with increased risk for insulin resistance," European Journal of Nutrition, vol. 48, no. 3, pp. 170-175, 2009.

[38] P. T. Annamala and K. T. Augusti, "Effect of glibenclamide, tolbutamide and insulin on serum, lipoprotein cholesterol fractions in alloxan diabetic rabbits," Indian Journal of Clinical Biochemistry, vol. 6, no. 2, pp. 105-108, 1991.

[39] C. M. Lenich, A. V. Chobanian, P. Brecher, and V. I. Zannis, "Effect of dietary cholesterol and alloxan-diabetes on tissue cholesterol and apolipoprotein E mRNA levels in the rabbit," Journal of Lipid Research, vol. 32, no. 3, pp. 431-438, 1991.

[40] N. K. Schiller and D. B. McNamara, "Balloon catheter vascular injury of the alloxan-induced diabetic rabbit: the role of insulinlike growth factor-1," Molecular and Cellular Biochemistry, vol. 202, no. 1-2, pp. 159-167, 1999.

[41] A. S. Fleitas, R. Simon, G. Almeida, A. M. Quintela, and M. A. Alfonso, "Modelo experimental de diabetes en conejos," Revista Cubana de Angiología y Cirugía Vascular, vol. 1, no. 1, pp. 10-14, 2000.

[42] M. Godwin, A. Olufunmilayo, O. Abraham, N. Crescie, and O. Abayomi, "The effect of aqueous root extract of Sphenocentrum jollyanum on blood glucose level of rabbits," Journal of Medicinal Plant Research, vol. 3, no. 11, pp. 870-874, 2009.

[43] K. Watters and P. Blaisdell, "Reduction of glycemic and lipid levels in $\mathrm{db} / \mathrm{db}$ diabetic mice by psyllium plant fiber," Diabetes, vol. 38, no. 12, pp. 1528-1533, 1989.

[44] S. A. Ziai, B. Larijani, S. Akhoondzadeh et al., "Psyllium decreased serum glucose and glycosylated hemoglobin significantly in diabetic outpatients," Journal of Ethnopharmacology, vol. 102, no. 2, pp. 202-207, 2005.

[45] Z. Madar, "Effect of brown rice and soybean dietary fiber on the control of glucose and lipid metabolism in diabetic rats," American Journal of Clinical Nutrition, vol. 38, no. 3, pp. 388393, 1983.

[46] A. C. D. Prias and V. C. Sgarbieri, "Guar gum effects on food intake, blood serum lipids and glucose levels of Wistar rats," Plant Foods for Human Nutrition, vol. 53, no. 1, pp. 15-28, 1998.

[47] T. K. Ray, K. M. Mansell, and L. C. Knight, "Long-term effects of dietary fiber on glucose tolerance and gastric emptying in noninsulin-dependent diabetic patients," American Journal of Clinical Nutrition, vol. 37, no. 3, pp. 376-381, 1983.

[48] T. Kawai, T. Ito, K. Ohwada, Y. Mera, M. Matsushita, and H. Tomoike, "Hereditary postprandial hypertriglyceridemic rabbit exhibits insulin resistance and central obesity: a novel model of metabolic syndrome," Arteriosclerosis, Thrombosis, and Vascular Biology, vol. 26, no. 12, pp. 2752-2757, 2006.

[49] T. M. S. Wolever, J. E. Campbell, D. Geleva, and G. H. Anderson, "High-fiber cereal reduces postprandial insulin responses in hyperinsulinemic but not normoinsulinemic subjects," Diabetes Care, vol. 27, no. 6, pp. 1281-1285, 2004.

[50] A. Flood, V. Mai, R. Pfeiffer et al., "The effects of a highfruit and -vegetable, high-fiber, low-fat dietary intervention on serum concentrations of insulin, glucose, IGF-I and IGFBP-3," European Journal of Clinical Nutrition, vol. 62, no. 2, pp. 186196, 2008.

[51] N. Wadood, M. Nisar, A. Rashid, A. Wadood, Gul-Nawab, and A. Khan, "Effect of a compound recipe (medicinal plants) on serum insulin levels of alloxan induced diabetic rabbits," Journal of Ayub Medical College Abbottabad, vol. 19, no. 1, pp. 32-38, 2007.

[52] W. P. M. Hopman, P. G. M. P. Houben, P. A. J. Speth, and C. B. H. W. Lamers, "Glucomannan prevents postprandial hypoglycaemia in patients with previous gastric surgery," Gut, vol. 29, no. 7, pp. 930-934, 1988.

[53] E. Fleischhacker, V. E. Esenabhalu, S. Holzmann et al., "In human hypercholesterolemia increased reactivity of vascular smooth muscle cells is due to altered subcellular $\mathrm{Ca}^{2+}$ distribution," Atherosclerosis, vol. 149, no. 1, pp. 33-42, 2000. 

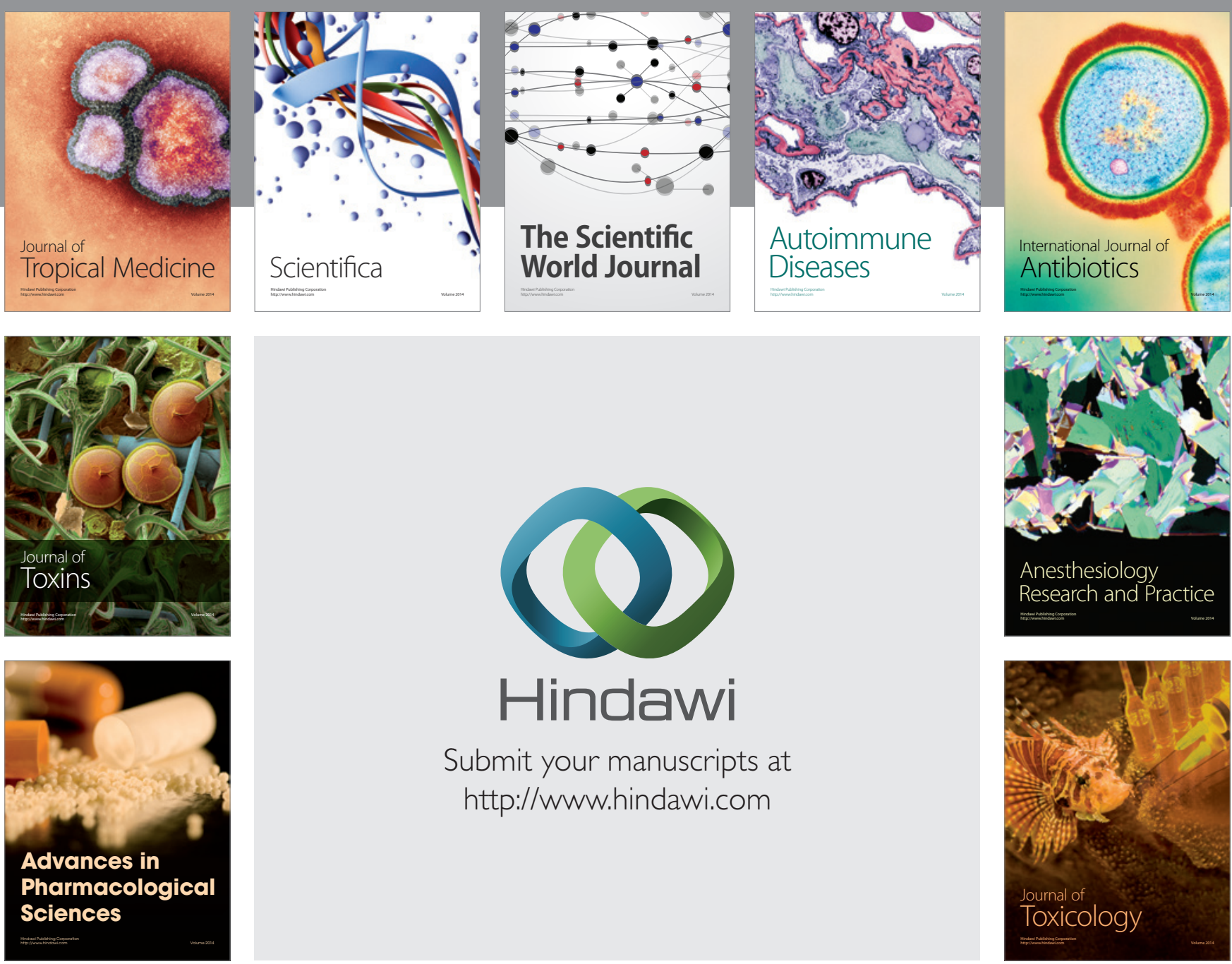

\section{Hindawi}

Submit your manuscripts at

http://www.hindawi.com
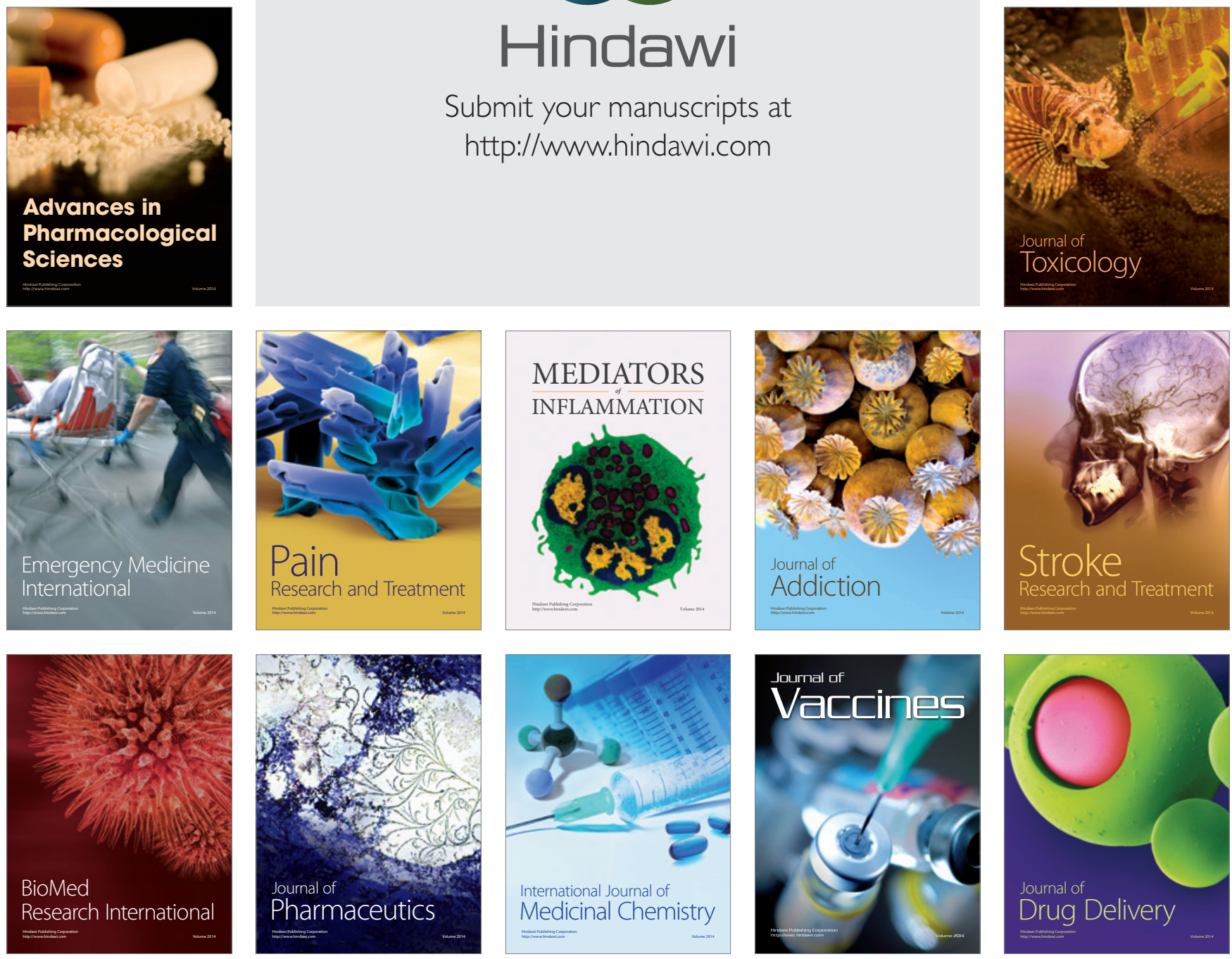